\title{
Wegener's Granulomatosis Presenting With an Isolated Paranasal Sinus Involvement in a Child
}

\author{
Ghaniya DAAR, ${ }^{1}$ Ali Bülent CENGİZ, ${ }^{2}$ Ateş KARA, ${ }^{2}$ Rezan TOPALOĞLU, ${ }^{2}$ \\ Ömer Taşkın YÜCEL, ${ }^{3}$ İsmail DURSUN ${ }^{4}$ \\ ${ }^{1}$ Department of Pediatrics, Medical Faculty of Bozok University, Yozgat, Turkey \\ ${ }^{2}$ Department of Pediatrics, Medical Faculty of Hacettepe University, İhsan Doğramacı Children's Hospital, Ankara, Turkey \\ ${ }^{3}$ Department of Otolaryngology, Medical Faculty of Hacettepe University, Ankara, Turkey \\ ${ }^{4}$ Department of Pediatrics, Medical Faculty of Erciyes University, Kayseri, Turkey
}

\begin{abstract}
Wegener's granulomatosis which is rarely seen in children is an idiopathic necrotizing granulomatous vasculitis, affecting primarily paranasal sinuses, nasopharynx, lungs, kidneys and joints. In this article, we report a very rare case of eight-year-old boy presenting with Wegener's granulomatosis of paranasal sinuses without lung, kidney and any other organ involvement. We discuss the diagnosis, treatment and the differential diagnosis of paranasal sinus involvement in Wegener's granulomatosis in the light of literature data.

Keywords: Child; paranasal sinus; Wegener's granulomatosis.
\end{abstract}

Wegener's granulomatosis (WG) is mostly seen in adults with ages between 20 and 50 without a sex predilection. It is a necrotizing granulomatous vasculitis mostly affecting the lungs (95\%), paranasal sinuses (90\%), kidneys (85\%), nose or nasopharynx (65\%), and joints (65\%) accordingly. ${ }^{1-4}$ It is rarely seen in children. ${ }^{5,6}$ Childhood WG has many common findings with those of adult disease, especially respiratory tract and renal involvement. However, the disorder has a female predominance in children and less frequently involves joints and paranasal sinuses. ${ }^{7}$ Paranasal and thorax computed tomography (CT) can be used to support the diagnosis. ${ }^{8,9}$ The definite diagnosis is based on the presence of necrotizing granulomatous vasculitis in pulmonary, renal or paranasal sinus biopsy specimens. ${ }^{5}$
Here we report a previously healthy boy who presented with facial edema, a history of recurrent upper respiratory tract infection and recurrent sinusitis without any other complaints and findings, and who was later on diagnosed as having WG limited to the maxillary sinuses, without other systemic involvement.

\section{CASE REPORT}

An eight-year-old boy was admitted to the Emergency Department of Hacettepe Children's Hospital with an overnight history of bilateral eye swelling accompanied by sore throat, rhinorrhea and mild fever. The patient had twoyear intermittent upper respiratory tract signs and symptoms such as a yellow-greenish thick nasal 
discharge and nasal congestion as well as crusty nasal mucosa.

Vital signs and physical examination findings were normal, except for hyperemic oropharyngeal mucosa and swollen bilateral lower eyelids and the cheeks. He had tenderness on palpation of the face. Complete blood count analysis results were as follows: hemoglobin $13.1 \mathrm{~g} / \mathrm{dl}$, white blood cell count $9,900 / \mathrm{mm}^{3}$, platelets $549,000 / \mathrm{mm}^{3}$. The peripheral blood smear showed 60\% polymorphonuclear cells cell, 36\% lymphocytes, and $4 \%$ monocytes with no toxic granulations. Full biochemistry as well as urinary parameters were within normal ranges. C-reactive protein values were 4.88 and $0.44 \mathrm{mg} / \mathrm{dl}$ range (0-0.6), while erythrocyte sedimentation rate values were 35 and $25 \mathrm{~mm} / \mathrm{hr}$ (range 0-20), measured before and after treatment, respectively. To rule out a possibility of an underlying allergic reaction, the patient was first treated with lowdose methylprednisolone and an antihistamine. Although the patient did not respond to this treatment, total immunoglobulin $\mathrm{E}$, nutritional and inhalant mixture tests were performed with normal results to remove suspected hereditary angioedema and other causes of $\mathrm{C} 1$ esterase inhibiton.

For further evaluation, paranasal CT was performed. The CT showed extensive bilateral opacifications and new bone formation within the maxillary sinuses, with sclerosis, thickening of sinus walls. There was an increased soft tissue thickening and reticulation within the periorbital, peri-zygomatic and premaxillary soft tissues consistent with edema and inflammation. The findings were thought to represent an aggressive and chronic inflammation such as chronic osteomyelitis (Figure 1). Until paranasal infection was ruled out, ampicillin/sulbactam and amikacin therapy were given.

The medical history with $\mathrm{CT}$ findings gave a suspicion of underlying WG. Further evaluation revealed normal chest X-ray findings and complement 3 (C3) and 4 (C4) values of $154 \mathrm{mg} / \mathrm{dl}$ (79-152) and $34 \mathrm{mg} / \mathrm{dl}$ (16-38), respectively. The anti-nuclear antibody (ANA) titer was $1 / 80$, anti-double stranded DNA (anti-dsDNA) was negative, and the myeloperoxidase antineutrophil cytoplasmic antibodies (MPO-ANCAs) was less than $2.0 \mathrm{U} / \mathrm{ml} \quad(<20)$. Cytoplasmic-staining antineutrophil cytoplasmic antibodies (c-ANCAs) and proteinase- 3 (PR3), was above $200 \mathrm{U} / \mathrm{ml}$ $(<20)$. Thoracic CT and renal ultrasonography produced normal results. Definite diagnosis was made by punch biopsy of the maxillary sinus wall. Examination of the biopsy material revealed chronic granulomatous inflammation with numerous multinuclear giant cells, foci of microabscesses, and vasculitis consistent with WG (Figure 2). Antibiotic treatment was
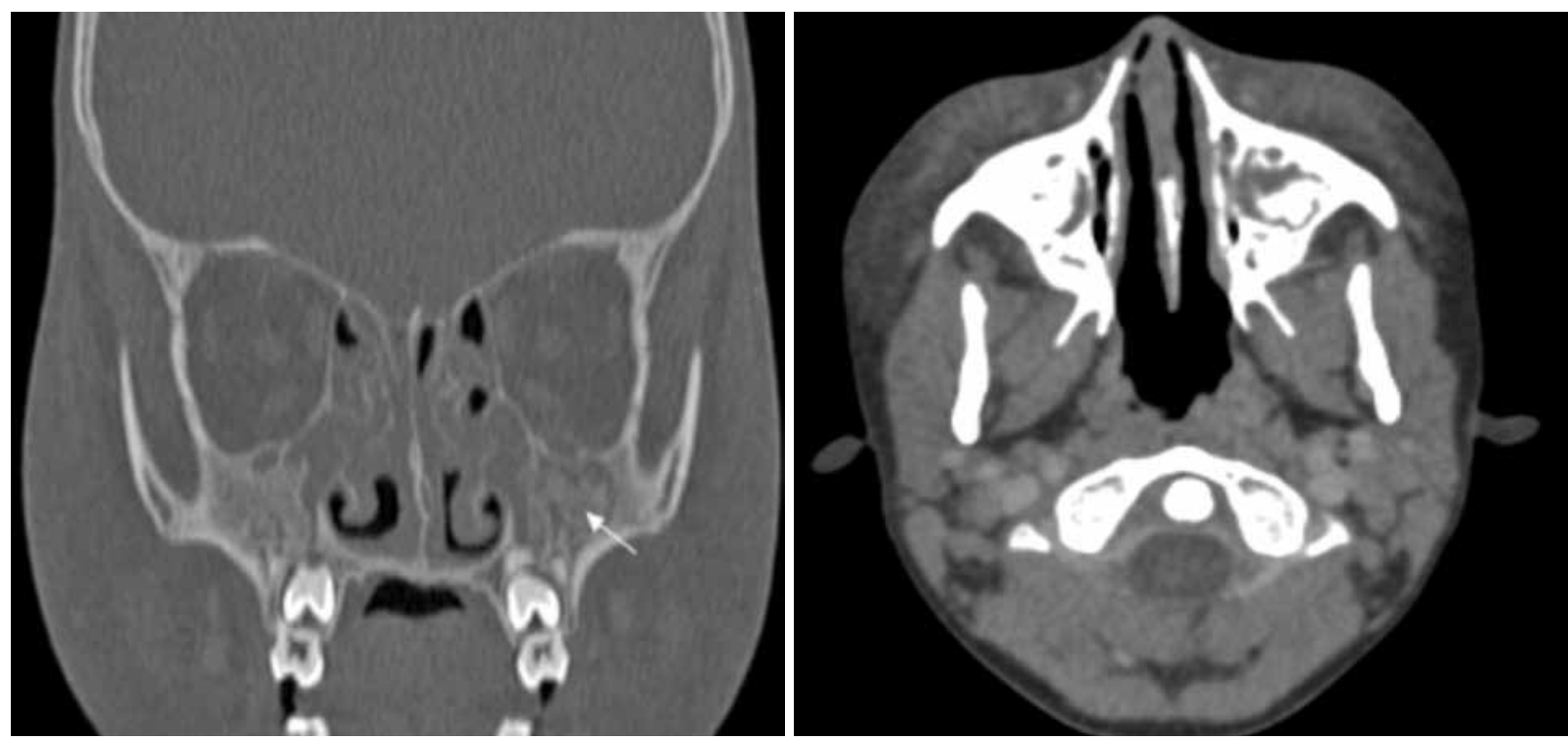

Figure 1. Paranasal computed tomography of the child showing extensive bilateral opacification and new bone formation within the maxillary sinuses with sclerosis, thickening of sinus walls. 


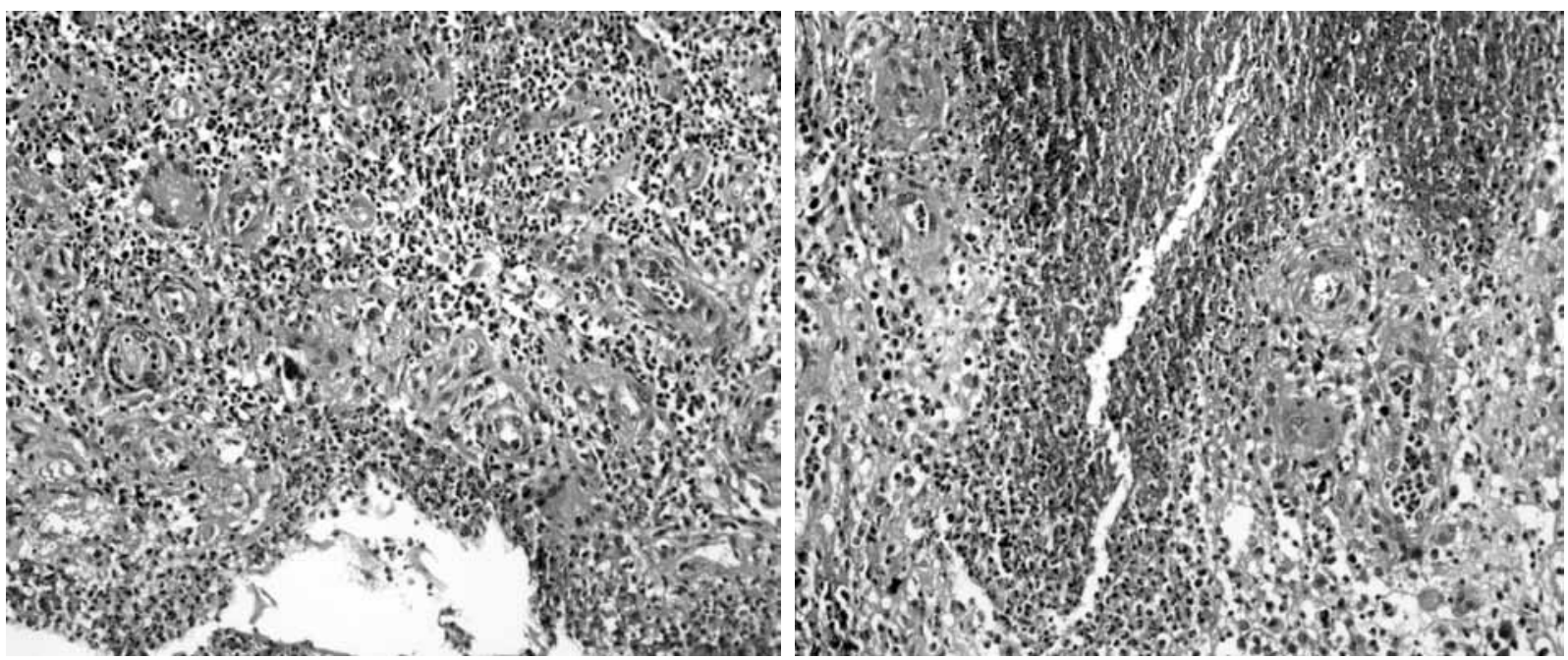

Figure 2. Maxillary sinus biopsy showing granulomatous inflammation with multinuclear giant cells and vasculitis (H-E x 40).

discontinued, while cyclophosphamide and prednisolone treatment was started.

In our follow-ups, the patient substantially recovered and continued low-dose prednisolone without any additional medication.

\section{DISCUSSION}

Wegener's granulomatosis is a rare disease of childhood. $^{5-7}$ In general, it involves the upper respiratory tract, lungs and kidneys. ${ }^{1-4,7}$ The etiology is unknown, 5,8 however probably multifactorial; autoimmune inflammatory process associated with infectious, environmental and genetic factors. ${ }^{5}$ Abnormal PR3 expression on neutrophil cell surfaces may be the main cause, and c-ANCA positivity is highly specific for WG. ${ }^{5}$ Non-specific laboratory findings including elevated erythrocyte sedimentation rate, $\mathrm{C}$-reactive protein, leukocytosis, thrombocytosis, anemia and hematuria may support the diagnosis. ${ }^{5,8}$ The c-ANCA positivity directed against PR3 specifies the diagnosis. ${ }^{5,6}$ Since critical organ involvement can be seen in the course of disease, diagnosis should be made correctly and as early as possible. Early management may lead to a prolonged remission period or even complete recovery. ${ }^{5,6}$

In a recent study conducted by Akikusa et al. ${ }^{7}$ the median age of 25 children with WG was 14.5 years old (range 8.7 to 17.1 years) and it was consistent with our case where the patient was eight years old. Although constitutional symptoms like fever (72\%), arthralgia (64\%) and weight loss (56\%) are frequently seen, only mild fever was present in our case. Though the renal and lower respiratory systems are frequently involved ( $88 \%$ and $80 \%$ respectively), ${ }^{7}$ our patient had only upper respiratory tract complaints with facial edema and mild conjunctival hyperemia without eye muscle or further orbital involvement. Unlike in our case, ocular involvement in WG has been reported in the literature. ${ }^{5,9}$

Simmons et al. ${ }^{10}$ using CT found that patients with sinonasal involvement have bilateral sinus opacification, concomitant orbital mass, bone erosion, septal perforation, and mucosal inflammation. Maxillary sinus involvement is mostly seen. ${ }^{11,12}$ In our case, the CT findings were similar to those of Simmons et al. ${ }^{10}$

In the differential diagnosis of maxillofacial diseases, preseptal cellulitis, orbital cellulitis, sinusitis, osteomyelitis, malignancies should be considered along with vasculitis involving the upper respiratory tract. ${ }^{5}$ Infectious causes such as cellulitis, acute sinusitis, and osteomyelitis can be easily differentiated by lack of fever in the disease course. In case of malignancy, the usual presentation includes unilateral mass, constitutional sign and symptoms, and poor general condition. ${ }^{5}$ Among c-ANCA positive 
vasculitis such as Goodpasture syndrome, microscopic polyangiitis and Church-Strauss syndrome,${ }^{5}$ WG can be differentiated by biopsy and PR3-ANCA positivity.,5,10 In our case, the diagnosis of WG was made by PR3-ANCA positivity along with granulomatous vasculitis in the maxillary sinus biopsy. Tuberculosis and sarcoidosis may also cause granulomatous lesions however, in these cases, c-ANCA is found to be negative. ${ }^{8}$

The treatment modalities of WG include use of immunosuppressive drugs such as corticosteroids, cyclophosphamide and methotrexate. ${ }^{5}$ Trimethoprim-sulfamethoxazole is used for prophylaxis. ${ }^{5,10}$ In this case, similar to the treatment modality used for the two WG cases of sinus and renal involvement by Singer et al., ${ }^{13}$ both prednisolone and cyclophosphamide were administered. The child is being followed-up in outpatient clinic without any complications or relapse with reduced doses of prednisolone therapy. He showed no relapse during six-month follow-up.

In conclusion, although WG is a rare disease of childhood, ${ }^{5,8,10}$ it should be considered in the differential diagnosis of recurrent upper respiratory tract illnesses. ${ }^{5,8,10}$ It is usually difficult to diagnose WG at an early stage, however, a careful medical history and close examination of signs and symptoms may help in the diagnosis of WG. An early diagnosis and treatment initiation would result in a longer remission period.

\section{Declaration of conflicting interests}

The authors declared no conflicts of interest with respect to the authorship and/or publication of this article.

\section{Funding}

The authors received no financial support for the research and/or authorship of this article.

\section{REFERENCES}

1. Wolff SM, Fauci AS, Horn RG, Dale DC. Wegener's granulomatosis. Ann Intern Med 1974;81:513-25.

2. Fauci AS, Haynes BF, Katz P, Wolff SM. Wegener's granulomatosis: prospective clinical and therapeutic experience with 85 patients for 21 years. Ann Intern Med 1983;98:76-85.

3. O’Devaney K, Ferlito A, Hunter BC, Devaney SL, Rinaldo A. Wegener's granulomatosis of the head and neck. Ann Otol Rhinol Laryngol 1998;107:439-45.

4. Kornblut AD, Wolff SM, deFries HO, Fauci AS. Wegener's granulomatosis. Otolaryngol Clin North Am 1982;15:673-83.

5. Frosch M, Foell D. Wegener granulomatosis in childhood and adolescence. Eur J Pediatr 2004;163:425-34.

6. Miller ML, Pachman LM. Vasculitis syndromes. In: Behrman RE, Kliegman RM, Jenson HB, editors. Nelson Textbook of Pediatrics. 17th ed. Philadelphia: Saunders; 2004. p. 830-1.

7. Akikusa JD, Schneider R, Harvey EA, Hebert D, Thorner PS, Laxer RM, et al. Clinical features and outcome of pediatric Wegener's granulomatosis. Arthritis Rheum 2007;57:837-44.

8. Haliloglu M, Karcaaltincaba M, Toru M, Kiper $\mathrm{N}$, Ariyurek MO. CT presentation of Wegener's granulomatosis in a child: rapidly progressive changes of pulmonary nodules to cavities. Eur $\mathrm{J}$ Radiol 2000;35:12-4.

9. Simmons JT, Leavitt R, Kornblut AD, Fauci AS. $\mathrm{CT}$ of the paranasal sinuses and orbits in patients with Wegener's granulomatosis. Ear Nose Throat J 1987;66:134-40.

10. Levi M, Kodsi SR, Rubin SE, Lyons C, Golden R, Olitsky $\mathrm{SE}$, et al. Ocular involvement as the initial manifestation of Wegener's granulomatosis in children. J AAPOS 2008;12:94-6.

11. Lohrmann C, Uhl M, Warnatz K, Kotter E, Ghanem $\mathrm{N}$, Langer M. Sinonasal computed tomography in patients with Wegener's granulomatosis. J Comput Assist Tomogr 2006;30:122-5.

12. Paling MR, Roberts RL, Fauci AS. Paranasal sinus obliteration in Wegener granulomatosis. Radiology 1982;144:539-43.

13. Singer J, Suchet I, Horwitz T. Paediatric Wegener's granulomatosis: two case histories and a review of the literature. Clin Radiol 1990;42:50-1. 